\title{
Utilization of antenatal care and its influence on fetal-maternal outcome: a tertiary care experience
}

\author{
Rajlaxmi Mundhra ${ }^{1}$, Ahanthem S. Singh ${ }^{1}$, Manika Agarwal ${ }^{1}$, Rakesh Kumar ${ }^{2}$
}

\begin{abstract}
${ }^{1}$ Department of Obstetrics and Gynecology, North Eastern Indira Gandhi Regional Institute of Health and Medical Sciences, Shillong, Meghalaya, India

${ }^{2}$ Department of Pediatrics, Hindu Rao Hospital, Delhi, India
\end{abstract}

Received: 11 October 2013

Accepted: 27 October 2013

\author{
*Correspondence: \\ Dr. Rajlaxmi Mundhra, \\ E-mail: rmundhra54@yahoo.com
}

(C) 2013 Mundhra R et al. This is an open-access article distributed under the terms of the Creative Commons Attribution Non-Commercial License, which permits unrestricted non-commercial use, distribution, and reproduction in any medium, provided the original work is properly cited.

\begin{abstract}
Background: To compare the sociodemographical characteristics, obstetrical complications, and fetal-maternal outcomes in booked and unbooked mothers.

Methods: In a prospective study over an 18 month period, outcomes of pregnancy booked for antenatal care were compared with that of unbooked women, who delivered in the Department of Obstetrics and Gynecology, NEIGRIHMS.

Results: 802 patients were recruited to study. 479 (59.73\%) were unbooked and 323 cases $(40.27 \%)$ were booked. Compared with booked mothers, majority of unbooked mothers belonged to lower social class, came from remote areas and had a significant higher incidence of teenage pregnancy and Grand multiparity. Unbooked mothers had higher incidence of anemia ( $\mathrm{p}<0.0001)$, pregnancy induced hypertension $(\mathrm{p}=0.033)$, post dated pregnancy $(\mathrm{p}<0.0001)$ and malpresentation $(\mathrm{p}=0.013)$. Three maternal deaths were noted in the unbooked group compared to only one death in the booked group. Overall, maternal morbidity was $4.74 \%$, with a significant difference between the two groups $(\mathrm{p}<0.0001) .10 .33 \%$ babies of unbooked and $6.12 \%$ of booked cases needed neonatal intensive care $(\mathrm{p}=$ 0.036). The incidence of meconium stained amniotic fluid, birth asphyxia, perinatal deaths, low birth weight and APGAR score $<7$ at $1 \mathrm{~min}$ and 5 min were significantly higher in babies of unbooked mothers.

Conclusion: Poor utilization of antenatal care is associated with adverse fetal and maternal outcome.
\end{abstract}

Keywords: Antenatal care, Booked mothers, Unbooked mothers, Maternal complications, Perinatal outcome

\section{INTRODUCTION}

Childbirth is a natural and physiological event. Though it acts as a rewarding event for majority of couples, yet it may turn out into a nightmare by an unforeseen complication.

India is one of those countries having high maternal and infant mortality rates. The major health care problem in India is inequitable distribution of available health resources between urban and rural areas, lack of penetration of health services to the social peripheries, and lack of awareness among the people about the need for utilization of these health facilities. A large proportion of Indian population lives in the peripheries and do not enjoy the benefits of modern curative and preventive health services.

Maternal complications and poor perinatal outcome are highly associated with non utilization of antenatal care and delivery care services and poor socio-economic conditions of the patient. The percentage of women who seek antenatal care at least once in their entire pregnancy period is $74 \%$ in India whereas only $37 \%$ have $>4$ antenatal visits. ${ }^{1}$ The reason for poor utilization of health care facilities in India is a matter of concern as many unbooked mothers are seen with dreaded complications. 
Recently much stress has been put by the Government of India on hospital delivery rather than home delivery to reduce the complications during labour.

Proportion of maternal and child health has been one of the most important components of Family Welfare Programme of the Government of India and the National Population Policy $2000 .^{2}$ Moreover, some financial assistance has also been given to mothers under the scheme of Janani Suraksha Yojana (JSY). However in spite of so many initiatives set up by the Government of India, the uptake of these services is far from universal even in settings where they are readily available.

With this impression, this study is planned to explore differences in maternal and perinatal outcomes among booked and unbooked cases in NEIGRIHMS.

\section{METHODS}

This study was carried out in the Department of Obstetrics and Gynecology, NEIGRIHMS over a period of eighteen months.

All cases who attended the labour room in labour after the period of viability of fetus i.e., after 28 weeks of gestation were taken as study group. The study population was divided into two groups: booked and unbooked.

Booked mothers were those who had attended antenatal clinic in our Institute according to the maternal and child (MCH) division (1994), National Child Survival and Safe Motherhood programme, Government of India, i.e., those mothers who had taken a minimum of three antenatal visits, $1^{\text {st }}$ visit at 20 weeks or as soon as pregnancy is known, $2^{\text {nd }}$ visit at 32 weeks and $3^{\text {rd }}$ visit at 36 weeks.

Unbooked mothers were those who had never taken prenatal care and come for the first time during this pregnancy in labour.

\section{Exclusion criteria}

1) All cases who had taken irregular antenatal checkups not fulfilling the criteria laid in the booked group were excluded.

2) Those who had taken antenatal checkups elsewhere.

3) Those who had delivered elsewhere but has presented with complications.

Detailed history, physical examination, maternal and perinatal outcome were noted in a pre designed proforma. The socio economic status was computed using the modified Kuppuswamy’s scale. ${ }^{1}$

Chi square test was used to assess the statistical significance between the variables. Associations were considered statistically significant at the $\mathrm{p}$ value $<0.05$ (two tailed).

\section{RESULTS}

Eight hundred and two patients were recruited to study: 479 cases $(59.73 \%)$ were unbooked and 323 cases $(40.27 \%)$ were booked.

The maximum number of cases was seen between 20-35 years. Incidence of teenage pregnancy in the unbooked group was $10.85 \%$ compared to $6.19 \%$ in the booked group. (52 unbooked vs. 20 booked; p < 0.05). 59 cases in the unbooked group were more than 35 years compared to 11 cases in the booked group, ( $12.32 \%$ vs. $3.41 \% ; \mathrm{p}<0.0001)$. The incidence of gravida $\geq 5$ was significantly different among the two groups. 119 cases in the unbooked group comprised gravida $\geq 5$ compared to only 43 cases in the booked group, $(24.84 \%$ vs. $13.31 \%, \mathrm{p}<0.0001)$. Majority of unbooked cases belonged to lower social class and came from remote areas.(table 1)

The occurrence of maternal risk factors among booked and unbooked mothers on admission is shown in table 2 . Compared with booked patients, unbooked patients had a statistically significant higher incidence of grand multiparity $(24.84 \%$ in unbooked vs. $13.31 \%$ in booked, $\mathrm{p}<0.0001)$; teenage pregnancy $(10.85 \%$ in unbooked vs. $6.19 \%$ in booked, $\mathrm{p}=0.023)$; pregnancy induced hypertension ( $8.56 \%$ in unbooked vs. $4.64 \%$ in booked, $\mathrm{p}=0.033)$; malpresentation $(6.26 \%$ in unbooked vs. $2.48 \%$ in booked, $\mathrm{p}=0.013$ ) and post dated pregnancy ( $7.31 \%$ in unbooked vs. $1.55 \%$ in booked ; $<<0.0001)$.

Spontaneous vaginal delivery was the major mode of delivery in the study. It was higher in unbooked cases than booked cases. (63.67\% vs. 59.75\%), though the difference was not statistically significant. Significant difference was noted in terms of instrumental delivery between the two groups. $(6.47 \%$ unbooked vs. $3.1 \%$ booked, $\mathrm{p}=0.03)($ Table 3$)$.

Overall maternal morbidity was $4.74 \%$. The difference was statistically significant among the two groups $(6.89 \%$ in unbooked vs. $1.5 \%$ in booked; $\mathrm{p}<0.0001)$. Most frequent morbidity was atonic post partum hemorrhage (PPH) occurring in $3.9 \%$ of unbooked and $0.3 \%$ of booked cases $(\mathrm{p}=0.001)$ (Table 4$)$.

Overall neonatal intensive care unit (NICU) admissions were $8.63 \%$. The difference in terms of NICU admissions among booked and unbooked cases was statistically significant (10.33\% unbooked vs. $6.12 \%$ booked; $\mathrm{p}=0.036)$. During Intrapartum period, meconium stained amniotic fluid (MSAF) was noted in $23.17 \%$ unbooked compared to $13.31 \%$ booked cases ( $\mathrm{p}<0.0001$ ). Babies born to unbooked mothers were more likely to have birth asphyxia (7.44 \% unbooked vs. $2.44 \%$ booked; $\mathrm{p}=$ 0.001). The relationship between Apgar score and booking status was also statistically significant $(\mathrm{p}=0.007)$ (Table 5). 
Table 1: Characteristics of study patients.

\begin{tabular}{|c|c|c|c|c|c|}
\hline & & \multicolumn{2}{|l|}{ Booked } & \multicolumn{2}{|c|}{ Unbooked } \\
\hline & & Number & Percentage & Number & Percentage \\
\hline \multirow{3}{*}{$\begin{array}{l}\text { Age group } \\
\text { (in years) }\end{array}$} & $<20$ & 20 & 6.19 & 52 & 10.85 \\
\hline & $20-35$ & 292 & 90.40 & 368 & 76.83 \\
\hline & $>35$ & 11 & 3.41 & 59 & 12.32 \\
\hline \multirow{6}{*}{ Social class } & Upper & 30 & 9.29 & 0 & 0 \\
\hline & Upper middle & 101 & 31.27 & 24 & 5.01 \\
\hline & Lower middle & \multirow{2}{*}{95} & \multirow[t]{2}{*}{29.41} & \multirow[t]{2}{*}{96} & \multirow[t]{2}{*}{20.04} \\
\hline & Upper lower & & & & \\
\hline & \multirow[b]{2}{*}{ Lower } & 97 & 30.03 & 359 & 74.95 \\
\hline & & 0 & 0 & 0 & 0 \\
\hline \multirow{2}{*}{$\begin{array}{l}\text { Distance from } \\
\text { NEIGRIHMS }\end{array}$} & Near $(<20 \mathrm{~km})$ & 200 & 61.92 & 168 & 35.07 \\
\hline & Far & 123 & 38.08 & 311 & 64.93 \\
\hline \multirow{4}{*}{ Gravida } & Primi & 122 & 37.77 & 180 & 37.58 \\
\hline & $2-4$ & 158 & 48.92 & 180 & 37.58 \\
\hline & $5-9$ & 39 & 12.07 & 103 & 21.50 \\
\hline & $\geq 10$ & 4 & 1.24 & 16 & 3.34 \\
\hline
\end{tabular}

Table 2: Maternal risk factors at the time of admission in labour room.

\begin{tabular}{|c|c|c|c|c|c|c|}
\hline \multirow{2}{*}{\multicolumn{2}{|c|}{ Risk factor }} & \multicolumn{2}{|l|}{ Booked } & \multicolumn{2}{|c|}{ Unbooked } & \multirow[t]{2}{*}{ p value } \\
\hline & & Number & Percentage & Number & Percentage & \\
\hline \multicolumn{2}{|l|}{ Parity $\geq 5$} & 43 & 13.31 & 119 & 24.84 & $<0.0001$ \\
\hline \multirow{2}{*}{ Age } & $<20$ & 20 & 6.19 & 52 & 10.85 & 0.023 \\
\hline & $>35$ & 11 & 3.41 & 59 & 12.32 & $<0.0001$ \\
\hline \multirow{2}{*}{ Post Caesarean } & Once & 32 & 9.91 & 29 & 6.05 & \\
\hline & Twice & 9 & 2.79 & 0 & 0 & \\
\hline \multicolumn{2}{|l|}{$\begin{array}{l}\text { Pregnancy induced } \\
\text { hypertension }\end{array}$} & 15 & 4.64 & 41 & 8.56 & 0.033 \\
\hline \multicolumn{2}{|l|}{ Malpresentation-total } & 8 & 2.48 & 30 & 6.26 & 0.013 \\
\hline \multicolumn{2}{|l|}{ Breech } & 8 & 2.48 & 22 & 4.59 & \\
\hline \multicolumn{2}{|l|}{ Transverse } & 0 & 0 & 3 & 0.63 & \\
\hline \multicolumn{2}{|l|}{ Face } & 0 & 0 & 4 & 0.83 & \\
\hline \multicolumn{2}{|l|}{ Brow } & 0 & 0 & 1 & 0.21 & \\
\hline \multicolumn{2}{|l|}{ Twin } & 4 & 1.24 & 6 & 1.25 & \\
\hline \multicolumn{2}{|l|}{ Post Dated Pregnancy } & 5 & 1.55 & 35 & 7.31 & $<0.0001$ \\
\hline \multicolumn{2}{|l|}{ Anemia $(\mathrm{Hb} \%<10 \mathrm{gm})$} & 71 & 21.98 & 265 & 55.32 & $<0.0001$ \\
\hline
\end{tabular}


Table 3: Mode of delivery.

\begin{tabular}{|c|c|c|c|c|c|}
\hline \multirow{2}{*}{ Mode of delivery } & \multicolumn{2}{|c|}{ Booked cases $(\mathrm{n}=323)$} & \multicolumn{2}{|c|}{ Unbooked cases $(n=479)$} & \multirow{2}{*}{ p Value } \\
\hline & Number & Percentage & Number & Percentage & \\
\hline $\begin{array}{l}\text { Vaginal delivery (excluding instrumental } \\
\text { and assisted breech delivery) }\end{array}$ & 193 & 59.75 & 305 & 63.67 & 0.26 \\
\hline Total instrumental & 10 & 3.1 & 31 & 6.47 & 0.03 \\
\hline Ventouse delivery & 3 & 0.93 & 11 & 2.29 & \\
\hline Forceps delivery & 7 & 2.17 & 20 & 4.18 & \\
\hline LSCS & 119 & 36.84 & 136 & 28.39 & 0.012 \\
\hline Assisted breech delivery & 1 & 0.31 & 7 & 1.46 & 0.153 \\
\hline Caesarean Hysterectomy & 0 & 0 & 0 & 0 & \\
\hline
\end{tabular}

Table 4: Maternal morbidity in terms of immediate postpartum complications.

\begin{tabular}{|c|c|c|c|c|c|c|}
\hline \multirow{2}{*}{\multicolumn{2}{|c|}{ Complication }} & \multicolumn{2}{|c|}{ Booked cases } & \multicolumn{2}{|c|}{ Unbooked cases } & \multirow{2}{*}{ p Value } \\
\hline & & Number & Percentage & Number & percentage & \\
\hline \multicolumn{2}{|c|}{ Atonic PPH } & 1 & 0.3 & 19 & 3.9 & 0.001 \\
\hline \multicolumn{2}{|c|}{ Cervical tear/ Laceration } & 0 & 0 & 1 & 0.21 & \\
\hline \multicolumn{2}{|c|}{ Pulmonary edema } & 0 & 0 & 1 & 0.21 & \\
\hline \multicolumn{2}{|c|}{ Wound infection } & 2 & 0.62 & 8 & 1.67 & \\
\hline \multicolumn{2}{|c|}{ Anemic Heart Failure } & 0 & 0 & 1 & 0.21 & \\
\hline \multirow{3}{*}{ LSCS } & Extension & 1 & 0.3 & 2 & 0.42 & \\
\hline & Bladder injury & 0 & 0 & 0 & 0 & \\
\hline & Anesthetic & 0 & 0 & 0 & 0 & \\
\hline \multicolumn{2}{|c|}{ Post partum cardiomyopathy } & 1 & 0.3 & 0 & 0 & \\
\hline \multicolumn{2}{|c|}{ Rectus sheath hematoma } & 0 & 0 & 1 & 0.21 & \\
\hline \multicolumn{2}{|c|}{ Total morbidity } & 5 & 1.5 & 33 & 6.89 & $<0.0001$ \\
\hline
\end{tabular}

Table 5: Perinatal morbidity.

\begin{tabular}{|lllllll|}
\hline \multirow{2}{*}{ Morbidity } & \multicolumn{7}{c}{ Booked case } & \multicolumn{2}{c}{ Unbooked case } & p value \\
\cline { 2 - 7 } & $\begin{array}{l}\text { Meconium } \\
\text { Intrapartum }\end{array}$ & 43 & 13.31 & 111 & 23.17 & $<0.0001$ \\
\cline { 2 - 7 } & $\begin{array}{l}\text { FHR } \\
\text { abnormality }\end{array}$ & 18 & 5.57 & 32 & 6.68 & 0.52 \\
\hline $\begin{array}{l}\text { After birth } \\
\text { Birth asphyxia }\end{array}$ & 7 & 2.14 & 36 & 7.44 & 0.001 \\
\hline Congenital abnormality & 0 & 0 & Pumber & percentage & \\
\hline Hyperbilirubinemia & 3 & 0.92 & 10 & 2.07 & 0.41 & \\
\hline
\end{tabular}




\begin{tabular}{|clllll|}
\hline Apgar score $(<7)$ At 1 min & 12 & 3.67 & 41 & 8.47 & 0.007 \\
\hline Apgar score $(<7)$ At 5 min & 10 & 3.06 & 36 & 7.44 & 0.009 \\
\hline Birth injury & 0 & 0 & 1 & 0.21 & \\
\hline Neonatal sepsis & 5 & 1.53 & 15 & 3.09 & \\
\hline NICU admission & 20 & 6.12 & 50 & 10.33 & 0.036 \\
\hline
\end{tabular}

Table 6: Perinatal mortality.

\begin{tabular}{|llllll|}
\hline \multirow{2}{*}{ Perinatal outcome } & \multicolumn{2}{l}{ Booked case $(\mathrm{n}=\mathbf{3 2 7})$} & Unbooked case $(\mathrm{n}=\mathbf{4 8 4})$ & p value \\
\cline { 2 - 5 } & Number & Percentage & Number & percentage & \\
\hline Intrauterine fetal death & 0 & 0 & 15 & 3.10 & \\
\hline Early neonatal death & 4 & 1.22 & 11 & 2.27 & \\
\hline Total mortality & 4 & 1.22 & 26 & 5.37 & 0.002 \\
\hline
\end{tabular}

Table 7: Birth weight distribution.

\begin{tabular}{|llllll|}
\hline $\begin{array}{l}\text { Birth weight } \\
\text { (in kg) }\end{array}$ & \multicolumn{2}{l}{ Booked cases $(\mathbf{n = 3 2 7})$} & \multicolumn{2}{l|}{ Unbooked cases $(\mathbf{n = 4 8 4})$} & p value \\
\cline { 2 - 3 } & Number & Percentage & Number & Percentage & \\
\hline $1-1.5$ & 0 & 0 & 1 & 0.21 & \\
\hline $1.5-2.5$ & 0 & 0 & 3 & 0.62 & \\
\hline Total LBW & 18 & 5.5 & 61 & 12.6 & $<0.0001$ \\
\hline $2.5-4$ & 303 & 5.5 & 65 & 13.43 & \\
\hline$\geq 4$ & 92.66 & 409 & 84.50 & \\
\hline
\end{tabular}

Perinatal mortality was $5.37 \%$ in unbooked and $1.22 \%$ of booked, the result being statistically significant $(\mathrm{p}=$ 0.002) (Table 6).

As evident from the table 7, $13.43 \%$ of unbooked and $5.5 \%$ of booked babies had birth weight less than normal $(\mathrm{p}<0.0001)$.

\section{DISCUSSION}

\section{Main findings}

In this study, a positive correlation between unbooked mothers with adverse feto-maternal outcome was observed.

\section{Strengths \& limitations of this study}

The major strength of this study included a large sample size .Certain limitations of this study should be noted. The study groups were divided into two groups based on inclusion criteria. But mothers who took antenatal care elsewhere and delivered in our institute were excluded. Similarly mothers who had home deliveries, whether or not they were antenatal clinic attenders would have been missed in this study. Mothers taking irregular antenatal care, for example visits in third trimester were also not included in this study. Also mothers booked for our hospital but delivered elsewhere but presented with complications were excluded. All this would have affected our results.

Moreover, the qualitative issues as to why the mothers avoided antenatal care were also not considered in the present study.

\section{Interpretation}

Consistent with Fawcus $\mathrm{SR}^{3}$ et al and Chigbu $\mathrm{B}^{4}$ et al, the present study showed that a higher percentage of unbooked mothers belonged to lower socio- economic 
status. Poor economic and education status may make it difficult for women to make informed decisions about using preventive and promotive health services, such as antenatal care particularly in an environment where the national poverty line is very high.

Also in agreement with findings in other studies (Harrison KA, ${ }^{5}$ de Jong $\mathrm{G}^{6}$ et al, Owolabi ${ }^{7}$ A T et al), a significantly higher percentage of the grand multiparous patients were unbooked in this study, most likely because these mothers had previous successful deliveries without antenatal care and therefore felt assured and did not feel the need to seek antenatal care in the pregnancy also.

Significant higher proportions of unbooked mothers were aged > 35 years and were of high parity. This could be attributed to their lower educational status and lower social class; as a result of which they were not aware of the need for birth spacing and the importance of contraceptive measures and as such, kept on becoming pregnant. This could also be the reason behind the higher proportion of unbooked mothers to be anemic as women having repeated pregnancies do not have time to replenish their iron stores before their next pregnancy.

In interpretation of our results, we found that unbooked mothers had adverse fetal and maternal outcome. But this study showed that the incidence of emergency caesarean section was significantly lower in the unbooked mothers compared to booked mothers $(28.39 \%$ vs. $36.84 \%)$. The reason behind this could be:

1. Many of the booked patients with complications like pregnancy induced hypertension, post caesarean status, primigravida with breech presentation attends labour room earlier and at the slightest and earlier detection of deviation from normal labour pattern undergo caesarean section.

2. Many of the booked patients had associated risk factors in the form of once or twice previous caesarean section, bad obstetric history, elderly primigravida not willing for vaginal birth, cephalo pelvic disproportion and contracted pelvis. Such cases were being planned for elective caesarean section but had to be taken as emergency cases as they came in early labour thereby increasing the caesarean section rate in booked mothers. The present study had 30 such cases which accounted for $9.28 \%$ caesareans in booked mothers. So if we exclude these cases from the booked caesareans there remains only $27.55 \%$ of emergency caesarean section in booked mothers which is quite similar to the unbooked caesarean section rate.

Overall maternal morbidity was $4.74 \%$ and the difference was statistically significant between the two groups. Association of lack of prenatal care with increased morbidity and mortality has been found in other studies.
Most frequent morbidity in the present study similar to that noted by Riffat et $\mathrm{al}^{8}$ was atonic PPH.

Unlike the study of Owolabi ${ }^{7}$ AT et al., this study showed a higher proportion of spontaneous vaginal delivery among the unbooked cases compared to booked (63.67\% vs. $59.75 \%$ ). Unbooked mothers had significantly higher incidence of instrumental deliveries in the form of outlet forceps application and Ventouse compared to booked mothers $(6.47 \%$ vs. $3.1 \%)$. The probable reason behind the higher incidence of instrumental deliveries in unbooked mothers was:

- Admission of unbooked patients in late $2^{\text {nd }}$ stage of labour with complications amenable to instrumental vaginal delivery.

On careful scrutiny of all the three unbooked maternal deaths, an interesting finding was observed. This was the presence of severe anemia in all the three deaths. Moreover, one of the deaths was due to anemic heart failure. This was, in fact, a case of unmarried, teenage pregnancy who presented to us in $2^{\text {nd }}$ stage of labour. This death is a totally preventable one and highlights the role of antenatal care. The other two deaths were due to pulmonary edema. Booked maternal death was due to post partum cardiomyopathy.

Frequency of birth asphyxia, LBW, MSAF, NICU admissions were significantly higher in unbooked mothers, as was the perinatal mortality rate. No case of intrauterine fetal demise was noted in the booked group, which again highlights the importance of antenatal care. Lack of antenatal care was associated with higher incidence of birth asphyxia in a study in Hyderabad. ${ }^{9}$ Similar results were obtained by Ekwempu et $\mathrm{al}^{10}$ and Treacy et al. ${ }^{11}$

\section{CONCLUSION}

Poor utilization of antenatal care is associated with adverse feto-maternal outcome. Antenatal care and its importance can be implemented through general and health education, developing infrastructure, transport and communication facilities. Most maternal deaths are preventable if complications are diagnosed and managed effectively in time. The classical three delays include delay in decision to seek help, delay in getting transport and delay in providing effective treatment.

Hence, targeted, integrated, patient friendly, affordable and accessible health services need to be delivered in an equitable manner so as to improve the outcome for many women and children.

Funding: No funding was required for this article Conflict of interest: No conflict of interest exists for this article 
Ethical approval: This study received ethical approval from Institutional research committee vide noNEIGR/IEC/29/2009

\section{REFERENCES}

1. Park K. Park's Textbook of Preventive and Social Medicine. $21^{\text {st }}$ edition. Jabalpur India. M/s Banarasidas Bhanot.2011

2. National population policy- 2000. Department of Family welfare. Ministry of Health and Family Welfare. Government of India, New Delhi.

3. Fawcus SR, Crowther CA, Van Baelen P, Marumahoko J. Booked and Unbooked mothers delivering at Harare Maternity Hospital, Zimbabwe: a comparison of maternal characteristics and fetal outcome. Cent Afr J Med 1992 Oct;38(10):402-8.

4. Chigbu B, Onwere S, Kamanu CI, Aluka C, Okoro O, Adibe E. Pregnancy outcome in Booked and Unbooked Mothers in South Eastern Nigeria East Afr Med J. 2009 Jun; 86(6): 267-71.

5. Harrison KA. Child bearing, health and social and social priorities: a survey of 22774 consecutive hospital births in Zaria, Northern Nigeria. $\mathrm{Br} \mathrm{J}$ Obstet Gynaecol 1985;92 suppl 5:1-119.
6. de Jong G, Pattinson RC, Odendaal HJ. Influence of perinatal care on stillbirths in patients of low socioeconomic class .S Afr Med J 1988;74:53-4.

7. Owolabi A T, Fatusi A O, Kuti O, Adeyemi A, Faturoti S O, Obiajuwa PO. Maternal complications and perinatal outcomes in booked and unbooked Nigerian mothers. Singapore Med J 2008; 49(7): 526-531.

8. Riffat Jaleel, Ayesha Khan. Obstetric morbidity in the Booked versus non booked patients- A comparative study at Lyari general Hospital. Pakistan Journal of surgery 2008;24(3):196-202.

9. Majeed R, Memon Y, Majeed F, Shaikh NP, Rajar UD. Risk factors of birth asphyxia. J Ayub Med Coll 2007;19(3):67-71.

10. Ekwempu CC. The influence of antenatal care on pregnancy outcome. Trop J Obstet Gynaecol 1998;1(1):67-71.

11. Treacy A, O’Donovan M, Byrne P. Perinatal outcome in unbooked women at the Rotunda Hospital. Ir Med J 2002;95(2):44-47.

DOI: $10.5455 / 2320-1770 . i j r \operatorname{cog} 20131222$

Cite this article as: Mundhra R, Singh AS, Agarwal M, Kumar R. Utilization of antenatal care and its influence on fetal-maternal outcome: a tertiary care experience. Int J Reprod Contracept Obstet Gynecol 2013;2:600-6. 